\title{
Premarital sex and school dropout in Kenya: Can schools make a difference?
}

\author{
Barbara Mensch \\ Population Council \\ Wesley H. Clark \\ Population Council \\ Cynthia B. Lloyd \\ Population Council \\ Annabel Erulkar \\ Population Council
}

Follow this and additional works at: https://knowledgecommons.popcouncil.org/departments_sbsr-pgy

Part of the Demography, Population, and Ecology Commons, Family, Life Course, and Society

Commons, Gender and Sexuality Commons, and the International Public Health Commons

How does access to this work benefit you? Let us know!

\section{Recommended Citation}

Mensch, Barbara, Wesley H. Clark, Cynthia B. Lloyd, and Annabel Erulkar. 1999. "Premarital sex and school dropout in Kenya: Can schools make a difference?" Policy Research Division Working Paper no. 124. New York: Population Council. 


\section{Premarital Sex and School D ropout in Kenya: Can Schools Make a D ifference?}

Barbara S. Mensch

Wesley H. Clark

Cynthia B. Lloyd

Annabel S. Erulkar 


\title{
Premarital Sex and School Dropout in Kenya: Can Schools Make a Difference?
}

\author{
Barbara S. Mensch \\ Wesley H. Clark \\ Cynthia B. Lloyd \\ Annabel S. Erulkar
}

\begin{abstract}
Barbara S. Mensch is Senior Associate, Wesley H. Clark is Staff Research Associate, and Cynthia B. Lloyd is Director of Social Science Research, Policy Research Division, Population Council, New York. Annabel S. Erulkar, is Associate, Gender, Family, and Development Program, Population Council, Nairobi.
\end{abstract}

The authors gratefully acknowledge the statistical advice provided by John Casterline and Mark Montgomery and the helpful comments of Carol Kaufman and Parfait Eloundou-Enyegue. Funding for this study was provided by a research grant from the National Institute of Child Health and Human Development to Barbara S. Mensch and Cynthia B. Lloyd and from a United States Agency for International Development (USAID) Cooperative Agreement with the Population Council. Donors who supported the field research include the Ford Foundation, USAID, the Wallace Global Fund, the Compton Foundation, and the United Nations Population Fund, Nairobi. An earlier version of this paper was presented at the 1999 Annual Meeting of the Population Association of America, 25-27 March, New York. 


\begin{abstract}
Although an overall decline has occurred in adolescent fertility in Kenya, the proportion of births to teenagers that occur prior to marriage is rising. At the same time that premarital sex and childbearing have increased, educational participation has expanded considerably, especially for girls. Using data from nearly 600 adolescents aged 12-19 in combination with data collected from 33 primary schools that the adolescents attended, this paper explores whether certain aspects of the school environment affect the likelihood of early and unprotected sex among adolescent girls and boys in three districts of Kenya. Because of the concern with "schoolgirl pregnancy" in Kenya, the paper also explores the temporal relationship between premarital sex and pregnancy on the one hand, and school dropout on the other.

The results suggest that, although neither the school nor the home influences whether boys engage in premarital sex, for girls a school characterized by girl-friendly teachers and a gender-neutral atmosphere, and a home containing female role models and the support of two parents, reduce the risk of premarital sex. On the other hand, girls are more likely to engage in premarital sex if they attend schools where considerable pressure to have sex is reported. The school environment also appears to have an impact on whether or not sexually active boys choose to use contraceptives. A gender-neutral environment leads to greater contraceptive use among boys, as do schools where students have greater knowledge of reproduction. Finally, even if certain school characteristics significantly affect the risk of premarital sex for girls, the data indicate that pregnancy is not the primary reason that girls leave school early.
\end{abstract}

This material may not be reproduced in any form without written permission from the authors. 
Adolescent sexual and reproductive behavior is changing in Kenya in ways that potentially undermine the physical health and social and economic wellbeing of young people. Moreover, the environment in which adolescents are currently growing up - with a greater premium on skill acquisition than existed in the past-means that the consequences of early sex and early pregnancy may be more severe now than they have been before. These consequences are potentially more problematic for girls, who are more vulnerable to sexually transmitted diseases (STDs) and HIV/AIDS as teens ${ }^{1}$ and who shoulder all of the burden of childbearing and most of the burden of childrearing. Until recently, marriage and childbearing among adolescent girls were not only the statistical norm in subSaharan Africa but also considered desirable (Bledsoe and Cohen 1993). As education has become more widespread, marriage and, especially, childbearing during the teenage years are increasingly mentioned as limiting formal schooling and reducing early training and work opportunities (Caldwell et al. 1992).

Although rising age at marriage has led to a decline in adolescent fertility in Kenya, the proportion of births to teenagers that occur prior to marriage is increasing. Demographic and Health Survey (DHS) data indicate that the fraction of women who have had a premarital birth before age 20 has risen from about 10 to 15 percent for older cohorts of women to approximately one-fourth for those 20-24 in 1993. Indeed, data indicate that age at marriage is rising more rapidly than adolescent childbearing is declining. Although about half of women aged 40-44 in 1993 were married by age 18, compared with less than 30 percent of those aged 20-24 (Blanc and Way 1998), 59 percent of women aged 40-44 had given birth by age 20, compared with 52 percent of 20-24-year-olds (Singh 1998). More than half of teenage childbearing in Kenya now results from a premarital conception.

Reliable data on trends in sexual activity prior to marriage are nonexistent. A comparison of age at first sexual intercourse with age at first marriage across age cohorts of women, however, reveals an increase in the gap between sexual initiation and marriage in Kenya that is consistent with a rise in premarital sexual 
activity (Blanc and Way 1998). Although sexual activity prior to marriage apparently is increasing among women, contraceptive use remains sporadic among never-married girls who are sexually active. Fewer than 10 percent of single women aged 15-19 who said they were currently sexually active report use of a modern method of contraception in the recent DHS. As for men, despite the absence of time-series data on age at first intercourse, the perception exists that, throughout sub-Saharan Africa, a young man "in the past [in contrast to the present] . . . might have had little opportunity for full sexual expression until his late twenties" (Bledsoe and Cohen 1993:85).

At the same time that premarital sex and childbearing have increased in Kenya, educational participation has expanded considerably, especially for girls. More than 95 percent of males and females aged 15-19 had ever attended school, compared with about 85 percent of males and 60 percent of females aged 40-44 (NCPD et al. 1994). The high childhood enrollment rates that now exist in Kenya fall off steadily during the teenage years, reaching roughly 57 percent by age 18 (Montgomery and Lloyd 1999). Moreover, although gender equity in school participation is found among 12-13-year-olds, a gap in attendance between boys and girls emerges and expands during adolescence such that 5 percent more boys than girls go to school at ages 14-15, 9 percent more at ages 16-17, and 23 percent more at ages 18-19 (Mensch et al. 1998).

Although no data are available with which to address the issue of whether the secular increase in school participation in Kenya has led to a rise in premarital sexual activity, the extent to which some schools, because of their particular characteristics, put girls, and possibly even boys, at greater risk of early and unprotected sex is examined here in rural areas of three districts of KenyaKilifi, Nakuru, and Nyeri. These districts are selected because they represent the range of adolescent schooling experience in the country. In addition to the conventional family and household factors associated with premarital sex and contraceptive use, the effect of variables that measure school quality are investi- 
gated. In particular, those aspects of the school environment are considered that might affect the likelihood of early and unprotected sex, such as perceptions of how boys and girls are treated in school, the level of harassment, and the extent to which the school provides information on family-life education. The temporal relationship between sexual behavior and school retention is also explored in order to determine whether premarital sexual activity and pregnancy generally take place prior or subsequent to leaving school. To place the analyses in a larger context, previous literature on premarital sex and contraceptive use among adolescents in subSaharan Africa and the link between premarital sex and schooling are first reviewed.

\section{Premarital SEX AND CONTRACEPTIVE USE AMONG ADOLESCENTS}

A considerable body of research exists on adolescent sexual behavior, but few studies have attempted to explain that behavior in a systematic fashion. Rather, investigations of adolescent sexual and contraceptive behavior in sub-Saharan Africa tend merely to document levels of sexual activity, number and age of sexual partners, and knowledge and use of contraceptive methods. ${ }^{2}$

As Table 1 indicates, ${ }^{3}$ published studies of adolescent sexuality in subSaharan Africa not only reveal strikingly different levels of premarital sex between boys and girls in all countries except Nigeria but also wide-ranging levels for each sex across countries, a finding duplicated in analyses of never-married young adults based on DHS data (Gage-Brandon and Meekers 1993; Meekers 1994). No doubt some of the between-country variability observed in Table 1 can be explained by different sampling designs and target populations. In particular, because all the studies report percent having premarital sexual experience as of the time of survey as opposed to percent sexually experienced by a specified age, variation in the age composition may affect the levels reported. In addition, as Gage-Brandon and Meekers (1993) point out, different definitions of marriage may undermine comparability across countries. 


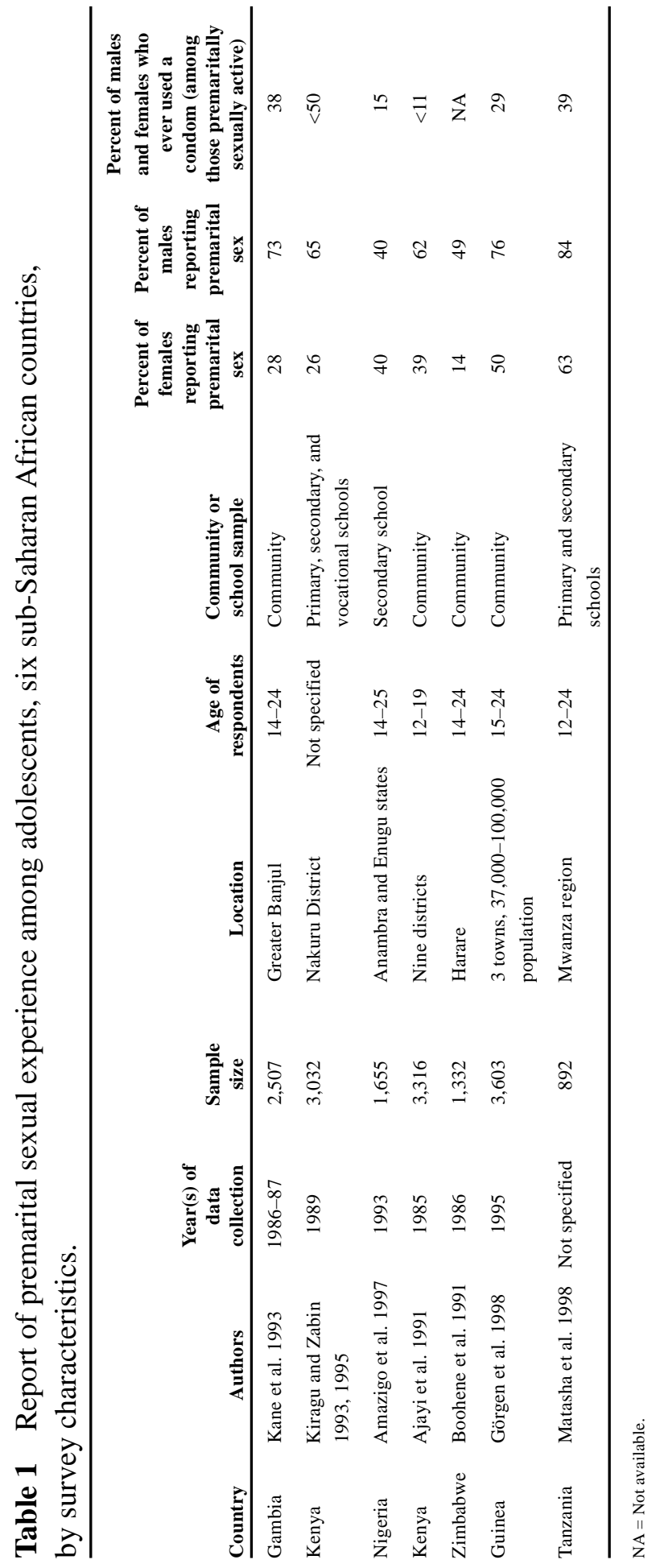


The range in sexual experience across countries is so wide that it raises questions about the accuracy of reporting. Even when data from the DHS are examined - where the issue of comparability of questionnaires, interviewing techniques, and sampling design is much less salient—substantial differences are found in reported levels of sexual activity (Meekers 1994). For example, among 15-19-year-old girls in eight Anglophone African countries, the proportion who are sexually experienced ranges from 26 percent in Nigeria to 60 percent in Kenya (Mensch et al. 1998). Is there a genuine difference, for example, between the behavior of adolescent girls in Zimbabwe and Zambia? Or are the 28 percent of girls who report premarital sex in Zimbabwe and the 50 percent in Zambia reflecting a greater willingness to acknowledge such behavior in one country compared with the other?

That some underreporting of adolescent sexual activity occurs in surveys is not unexpected. The embarrassment that adults — even young adults—face when questioning other adults on sexual issues is likely to be compounded when older interviewers try to obtain firsthand information from adolescents about their sex lives. Young people, especially girls, find great difficulty in admitting to having sex outside a socially sanctioned relationship, especially marriage. This difficulty is particularly acute in countries such as Kenya where the Catholic Church is extremely influential, where premarital abstinence is aggressively promoted, and where a pregnancy out of wedlock means expulsion from school. In contrast to girls, boys may overreport sexual activity because such experience is considered a badge of honor among men and a necessary rite of passage on the road to adulthood (Erulkar and Mensch 1997).

\section{Determinants of Sexual Activity}

One of the few studies that investigate the determinants of sexual behavior in sub-Saharan Africa is Kiragu and Zabin's 1993 analysis of approximately 3,000 adolescents attending primary, secondary, and vocational schools in Kenya. Al- 
though the study is noteworthy in going beyond purely descriptive tabulations and in focusing on primary as well as secondary school, it has several limitations. First, the analysis is restricted to students, ignoring the possibility that those who have dropped out of school may behave differently from those who are still enrolled. Second, seven of the 12 so-called explanatory variables included in the model—namely, religiosity, peer influence, substance use, disco attendance, attitude toward premarital sex, attitude toward birth control, and academic achievement-are endogenous, that is, the same factors that explain variability in levels of premarital sex would likely explain differences in these other variables. As a result, the coefficients and standard errors for these variables as well as for the exogenous variables may be biased. Third, the analysis fails to consider that many of the young people who still have not had sexual intercourse ultimately will engage in premarital sex during adolescence. Ignoring censored observations (that is, the young adolescents who delay sex) can result in biased parameter estimates if the determinants of early sex differ from those of late sex.

Of the variables in the Kiragu and Zabin analysis that are exogenousage, pubertal status, school location, living arrangements, and a measure of friction between the respondent's mother and father-all are significant for both sexes except parental conflict for boys. Adolescents who are older, postpubescent, attend schools in rural areas, reside at boarding schools (boys) or with adults other than their parents (girls), and whose families can be characterized as being in conflict (girls) are more likely to be sexually experienced.

Another investigation of the determinants of premarital sexual relations was undertaken by Meekers (1994) using DHS data from seven sub-Saharan African countries. The analysis, although not statistically flawed, was limited by the number of explanatory variables available in the surveys. Significant predictors of premarital sex among ever-married women in at least four of the seven countries were: religion, year of first marriage, and age at first marriage. In general, Muslims and those who married longer ago and at a younger age were less 
likely to have experienced premarital sex. Coefficients for the other variablesliteracy, place of residence, and age group-were either not significant or varied by country. Even fewer significant predictors emerged in a second model of the determinants of sexual experience among the never-married.

\section{Levels and Determinants of Contraceptive Use}

Reported levels of modern contraceptive use differ among adolescents in sub-Saharan Africa, although the variation among countries is not as great as that for premarital sex. Table 1 indicates the percentage of sexually active young people of both sexes who have ever used a condom, the most effective method for preventing transmission of HIV and other STDs and, therefore, recommended for unmarried adolescents. For all countries for which the percentages could be obtained or computed, fewer than half of sexually active adolescents have ever used a condom. If use at last sex were considered, the proportion would be lower, in most cases considerably so.

As with premarital sex, although numerous studies of the level of contraceptive use among young people in sub-Saharan Africa have been conducted, few analyses of the determinants of contraceptive use have been undertaken. Two studies with such analyses that have been conducted-Kane et al. (1993) and Kiragu and Zabin (1995) — advance our body of knowledge, but suffer from the same statistical weakness: Endogenous variables are included in the models. Variables such as attitude toward contraceptive use (Kiragu and Zabin 1995), frequency of sexual intercourse (Kiragu and Zabin 1995), desired number of children (Kane et al. 1993), pregnancy experience (Kane et al. 1993), and attendance at family-life education (FLE) lectures (Kane et al. 1993) are problematic for different reasons: (1) Including attitudes toward contraception in a model predicting use is almost tautological. (2) Frequency of sexual intercourse may well be a function of whether a contraceptive method is being used. (3) As with attitudes toward use, a variable such as desired family size is likely to be determined 
by the other variables in the model. (4) Because pregnancy experience is not timed relative to the dependent variable, whether the respondent or respondent's partner has been pregnant is as likely to be a result of contraceptive-use status as it is a determinant. (5) Finally, although the authors claim that exposure to FLE is exogenous, this variable may well be endogenous because not all respondents are required to attend lectures in school and because some can choose to attend lectures provided by the community outside school.

Although models of sexual activity and contraceptive use are often flawed, and reporting of sexual activity problematic, inferences from the descriptive analyses seem entirely plausible. Indeed, despite varying levels of sex and contraceptive use reported in these studies, the conclusions are similar: Substantial numbers of adolescents in sub-Saharan Africa are engaging in premarital sex with insufficient knowledge of reproduction and alarmingly low use of family planning methods, especially condoms.

This research has contributed to our understanding of the risks and dangers that adolescents face. However, it has paid little attention to the social context of adolescent sexual activity. What factors lead adolescent girls and boys to have sex? Are there, as Bledsoe and Cohen theorize, evolving sexual expectations and liberties for boys and increasing pressures and hazards for girls? In addition to household factors, what characteristics of schools, to which increasing numbers

of adolescents in sub-Saharan Africa are exposed, promote sexual activity and what characteristics discourage it?

\section{PREMARITAL SEX AND SCHOOLING}

Given the fluidity of the traditional African marriage process, the onset of sexual relations and childbearing prior to formalizing a union was not unknown in Kenya in the past (Meekers 1992). The rapid expansion in education has led, however, to an increasing association in the public mind between premarital sexual activity, childbearing, and schoolgirl dropout. For example, a recent conference 
of government ministers from the region devoted to this subject was entitled "Counting the Cost: School Dropout and Adolescent Pregnancy." Indeed, in drawing attention to the rise in premarital fertility, policymakers and researchers describe the situation in terms of increasing levels of "schoolgirl pregnancy"4 (Njau and Wamahiu 1994; Ferguson 1988; Meekers 1994; Meekers et al. 1995; Meekers and Ahmed 1999).

Because of the large number of school dropouts of all ages in Kenya and because reported dropouts due to pregnancy appear to represent only about 1 percent of girls currently enrolled in school each year, ${ }^{5}$ pregnancy is unlikely to be the leading proximate cause of girls' leaving school early. Although the assumption is often made that girls who are forced to withdraw because of pregnancy would have continued in school had they not become pregnant (see, for example, Meekers and Ahmed 1999), many other reasons may cause a girl to withdraw from school during her adolescence. The absence of social and economic opportunities for girls and women and the demands placed on them, coupled with the gender inequities known to exist within the educational system (Mensch and Lloyd 1998), may result in unsatisfactory school experiences, poor academic performance, and resignation to or preference for early motherhood. Therefore, although pregnancy is often thought to disrupt the education of adolescent girls, teenage reproductive behavior may be endogenous to school completion in that many of the same factors lead to dropout and early childbearing (Lloyd and Mensch 1999).

The question remains whether the increase in school enrollment-which has undoubtedly contributed to the rise in age at marriage and thus lengthened the period of exposure to the risk of premarital sex-has intensified the contact between adolescent girls and boys, undermined the authority of parents, and increased the likelihood that an adolescent girl will have premarital sex. Zabin and Kiragu (1998: 215) speculate that in sub-Saharan Africa, "schooling may actually encourage sexual onset, especially as it tends to remove young people from 
the supervision of traditional caretakers." Indeed, Bledsoe and Cohen (1993) attribute the increase in premarital sexual activity to schooling and employment opportunities available to young men, which give them greater independence from their families and wider sexual access to young women. In the past, sexual activity was regulated by the community. For example, among the Kikuyu in Kenya, newly circumcised young men and women were taught how to practice ngwiko, nonpenetrative stimulation of the sexual organs prior to marriage (Kenyatta 1971), which permitted sexual release but reduced the risk of pregnancy. Now, according to Bledsoe and Cohen (1993), boys have heightened expectations and make sexual demands on girls away from the watchful eyes of their elders.

Although schooling undoubtedly increases the level of unsupervised interaction of a perfectly benign or consensual sort, evidence exists that the type of attention girls receive from boys is often offensive and unwanted. Qualitative and quantitative data collected by the authors and their colleagues indicate that considerable harassment of girls of both a sexual and nonsexual nature takes place in Kenyan schools (Mensch and Lloyd 1998). Recent reports of a mass rape of schoolgirls, by no means the first to be publicized (Munyiri and Mwati 1996), are further evidence of the existence of nonconsensual sexual activity within schools. A national survey of nearly 10,000 secondary schoolgirls indicated that, of the one-third reporting sexual activity, approximately 40 percent said that their first encounter was forced or that they were "cheated into having sex" (Youri 1994; Mensch et al. 1998). Although the extent to which such encounters have occurred in transit to or from school is unknown, of the approximately 1,350 girls who said they were forced or cheated into having sex, about 70 percent said their first partner was a male student "about my age" or "older than myself." Only 5 percent said the first sexual partner was an adult male or older male relative. ${ }^{6}$ 
The expansion in schooling may have led to increased rates of sexual activity among girls in sub-Saharan Africa for yet another reason. The imposition of school fees, which include not only tuition but also charges for uniforms and textbooks, may force girls whose parents cannot afford to educate all their offspring or who are expected to be financially independent by virtue of their student status to acquire older sexual partners. Such "sugar daddies" or "sponsors" give girls money for school expenses and other needs in exchange for sexual favors (Bledsoe 1990; Odaga and Heneveld 1995; Meekers and Calvès 1997).

Here, the determinants of premarital sex are investigated as well as the determinants of contraceptive use among those who are sexually experienced. As indicated above, in addition to identifying individual and family characteristics associated with the initiation of premarital sex, the relationship between school quality and sex is also explored. To the extent that researchers have paid attention to the potential link between schooling and sexual behavior of adolescents, the analyses simply distinguish between young people in and out of school. To the authors' knowledge, no study has investigated the impact of school quality on the timing of first sex. Even research on the effect of school characteristics on enrollment, retention, and attainment has been limited in scope, focusing on a standard list of material inputs such as the state of facilities, instructional materials, and the number and quality of teaching staff.

For their earlier work on the effect of school quality on school dropout, the authors developed a conceptual model of the educational process that includes "material inputs" as well as variables that measure "time to learn," such as time spent in school and time lost to teachers' absences (Mensch and Lloyd 1998; Lloyd and Mensch 1999). The traditional model is extended here to include a third dimension labeled "school and classroom dynamics" that incorporates various characteristics of the school and classroom environment beyond pedagogical practices, a standard element within the school-effectiveness literature. This di- 
mension, which encompasses school policies, how students are treated, and underlying attitudes of teachers, is missing from the literature on school effectiveness, yet is highly relevant here. Elements of school and classroom dynamics reflect gender systems operating at the school level. Those elements that are either different for girls and boys or that have a potentially different effect for girls and boys are identified here. The argument is made that "a successful transition to adulthood is one in which a young person is allowed to grow to develop her or his full potential physically, intellectually, and emotionally before taking on adult roles" (Lloyd et al. 1998:10). School, because it is the most important socializing institution outside the family, may play a significant role in certain aspects of this transition to adulthood, including the decision to engage in premarital sex and the decision to practice contraception (Mensch and Lloyd 1998; Lloyd and Mensch 1999). The nature of the school a girl or boy attends is hypothesized to be important because of the negotiation process around sex. According to descriptions of this process in Kenya, girls "give in" to boys in exchange for gifts, money, or safe transit (Erulkar and Mensch 1997). Thus the authors speculate that those schools which are more supportive of girls, because there is both less sexual harassment and greater encouragement of academic achievement, equip them with the facility to ward off unwanted attention from boys.

A fourth dimension of school quality - availability of and attitudes toward family-life education - was also included in the model because of its potential relevance to adolescent behavior. The provision of reproductive health information in schools may affect sexual behavior and contraceptive use. For the analysis here, school-quality variables are limited to those measuring this fourth dimension and the third dimension, school and classroom dynamics.

This paper considers the effect of primary-school quality as it was measured at the time of the survey on premarital sex that had occurred at various times in the recent past. Because of late entry, grade repetition, and the limited 
number of places in secondary school, the vast majority of schoolgoing adolescents in Kenya attend primary school. Thus, the analysis here is restricted to the data from primary schools. The limitations of a cross-sectional survey mean that school quality must be assumed to change little over time, or alternatively, if a shift in quality occurs, all schools must be assumed to experience the same magnitude and direction of change. Also, implicit in the model is the notion that primary-school quality has an enduring impact. Thus even if an adolescent is no longer attending primary school when sexual initiation occurs-and many respondents in our sample are not (see the discussion below on premarital sex and school dropout)—whatever occurred in primary school is considered to have had an effect on decisions and behavior throughout the transition to adulthood.

\section{DATA}

The data for this study are drawn from a two-part, linked, community and school survey conducted in three rural districts of Kenya in mid-1996. The districts chosen were picked to maximize the range of school quality observed in Kenya, with Kilifi being at the low end of the spectrum, Nakuru the middle, and Nyeri the high. The selection was based on 1993 rankings of the Kenya Certificate of Primary Education, the primary school-leaving exam, and primary- and secondary-school enrollment data. Clusters within districts were then selected from the national sampling frame to reflect the high, middle, and low end of the educational range as well as to maximize the overlap of adolescents from the community-based sample with the schools they attend. ${ }^{7}$

The first part of the survey involved household interviews with 774 adolescents aged 12-19. In each of the 19 clusters selected, all households with a resident adolescent were identified for interview. In households with more than one adolescent, one was randomly selected for the interview from the previously collected household lists (see Note 7). Information was collected on family back- 
ground, educational history, time use, puberty, sexual experience, reproductive knowledge and behavior, drug use, delinquency, gender-role attitudes, self-esteem, and aspirations. For each preselected adolescent, a parent or responsible adult was also interviewed. All interviewing was undertaken in as private an environment as possible. Because the study area was rural, finding a private place to administer the questionnaire was usually not difficult. Most interviewing took place in farms or fields. If the selected adolescent was not home when the interviewer visited the household, an appointment was made for a time when the adolescent would be available. If necessary, interviewers revisited each household at least three times. Those who were away at boarding school were interviewed at the completion of the school term. (See the appendix for a discussion of the fieldwork and the sample-completion rate.)

Although a fairly even distribution of boys and girls was obtained for the adolescent sample—381 or 49 percent are girls and 393 or 51 percent are boys- too few 19-year-olds were obtained for the interview. Because of the positive rate of growth of the population-Kenya is growing by about 2 percent per year-the authors expected to locate more younger than older adolescents. However, the difference in the number of 19-year-olds compared with that of 17- and 18-year-olds is too great to be explained by smaller cohorts at older ages. Whereas 12 percent of the boys are 17 and 12 percent are 18, only 7 percent are 19. Similarly, 11 percent of girls are 17, 12 percent are 18, and 8 percent are 19. One explanation for the small number of 19-year-olds is misreporting of respondents' ages. Typically, in surveys for which the upper age of the target sample ends in 9, the number of respondents at the boundary is artificially small because respondents who do not know their ages, round to the nearest $10{ }^{8}$ Another explanation is that 19-year-olds are highly mobile and may have migrated between the time of the listing and the time of the interview. Thus, the 19-year-olds who were captured may be selective to some degree, a circumstance that, as is discussed below, may bear on their reports of sexual activity. 
The second part of the survey involved visits to 36 primary and 15 secondary schools attended by sample adolescents. The names of the schools that were visited were identified by adolescents in the community-based survey. Each school was visited by a three-person team for two to three days. In addition to an interview with the head teacher and the observation of school facilities, four English and four math classes were observed. The teachers who were observed were also interviewed, and a self-administered questionnaire was given to a random sample of 30 boys and 30 girls. Overall, 76 percent of the adolescents in the household survey had attended or were currently attending one of the 36 primary schools in the sample. Primary school in Kenya consists of eight grades or standards. The assessment of school quality was focused on standards 7 and 8, the last two years of primary education. For further details of the sampling design and the survey, see Ajayi et al. (1997) and Mensch and Lloyd (1998).

The descriptive analysis and the analysis in which household variables were selected to be used in the multivariate model of the determinants of premarital sexual activity are based on the entire sample of adolescents. The analysis, which includes school variables, is based on those adolescents who attended one of the 33 mixed-sex primary schools in the sample. ${ }^{9}$ The contraceptive model is based on the subset of adolescents who reported having had premarital sex and who attended one of the primary schools in the sample.

Because the analysis is restricted to adolescents who attended a primary school that was visited, a potential problem with selectivity exists. A comparison of the adolescents whose schools were visited with the adolescents whose schools were not visited revealed two significant differences: in age and in the household-possessions index; the older the adolescent and the higher the standard of living of his/her household, the more likely was the family to have moved away from the area in which the primary school was situated or alternatively, the more likely was the adolescent to be sent away to school (see Lloyd et al. 1998). 


\section{The Reliability of Data on Premarital Sexual Activity}

Because the topics to be explored were particularly sensitive, prior to development of the survey questionnaire, a small-scale qualitative study was undertaken among young people in the study communities. Fourteen focus-group discussions, segregated by age and sex, were conducted with 139 adolescents. The objectives were: (1) to understand how best to ask sensitive questions of young people in order to elicit the most accurate responses; (2) to identify possible markers and proxies for those behaviors; and (3) to understand what sort of interviewer would be most effective in putting the adolescent respondents at ease.

Young people have an extensive slang vocabulary for concepts and behaviors related to sex. This language is often used in the context of jokes and is considered appropriate to use among peers only and is not used with outsiders, including survey interviewers. The phrase "playing sex" (kufanya mapenzi) is the most commonly accepted expression for sexual intercourse among Kenyan adolescents. In order to encourage reporting, the questions on sexual activity were introduced with an acknowledgment of the different circumstances in which sex takes place: "Sometimes young people play sex. They play sex for different reasons-for love, or because they are convinced, forced, or tricked."

Before analyses of the determinants of premarital sexual activity are presented, descriptive data on premarital sex for both girls and boys are shown. Figure 1 compares the probability of premarital sex separately by district and sex. Because the experience of many of the adolescents in the survey is censored, this graph is based on a life-table analysis.

As suggested above, premarital sexual activity for girls, even if common, is not sanctioned in much of sub-Saharan Africa. Therefore, the reliability of data presented here is uncertain. Separate life tables were produced according to district because any differentials that emerged might shed light on the extent of underreporting. In both Kilifi and Nyeri districts, girls report significantly lower 
Figure 1 Probability of adolescents' engaging in premarital sex, by district, Kenya, 1996
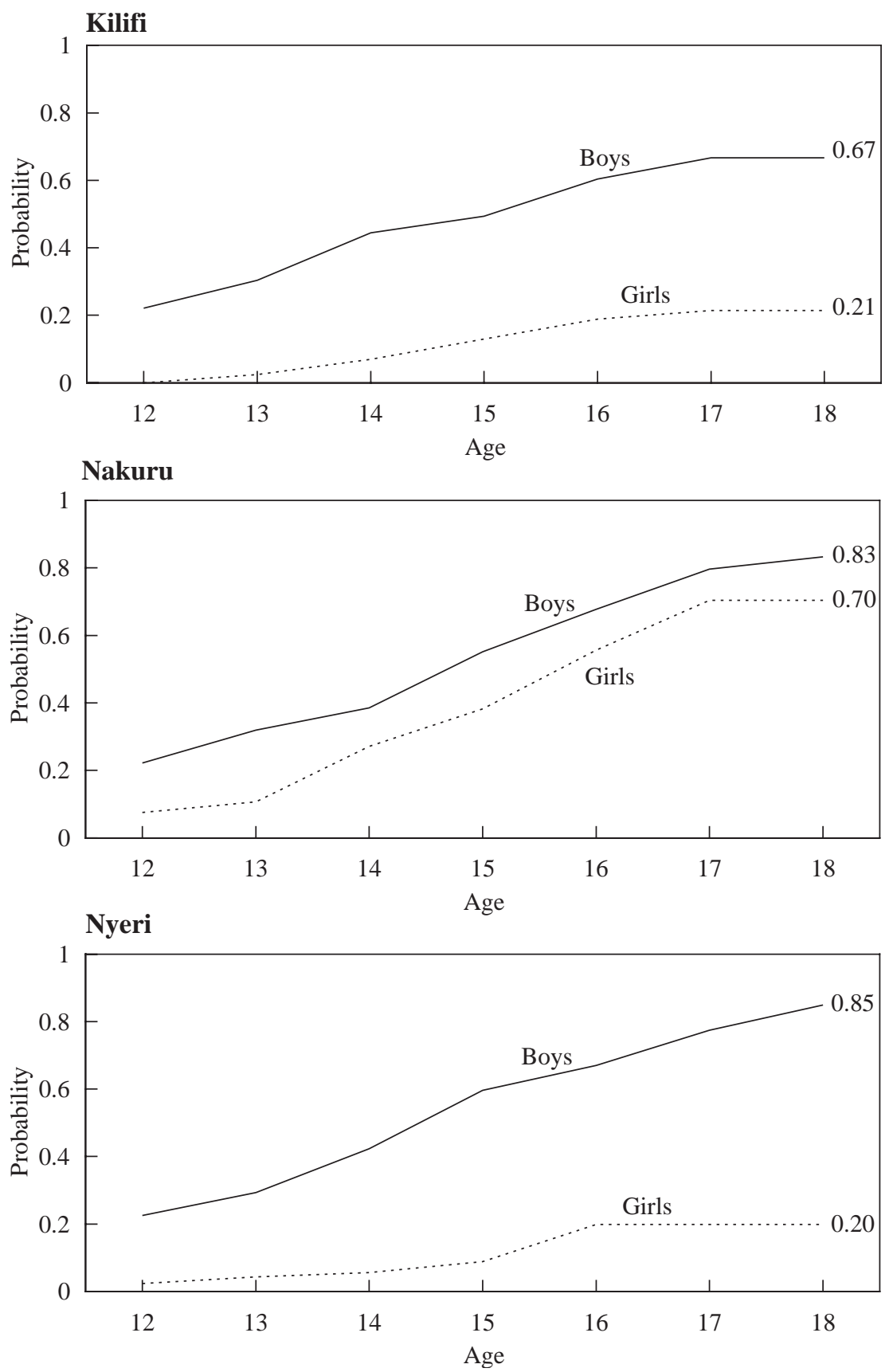
levels of premarital sexual activity than do boys, whereas in Nakuru the sex difference is much smaller. The authors believe that girls in Kilifi actually are less likely than boys to have sex. Kilifi is located in Coast Province, which is arguably the poorest and most conservative province in the country, with the lowest median age at marriage, the lowest level of female employment, and the lowest level of male approval of family planning (NCPD et al. 1999). Moreover, it has a substantial Islamic minority (about 20 percent of adolescents in the study sample). Kilifi is an area where girls still marry early, are less likely to attend school, and are monitored more closely than are girls in other areas of Kenya. On the other hand, it is suspected that girls in Nyeri have higher levels of premarital sex than they report, levels comparable to Nakuru. One explanation for the differences in reporting between the two districts may be that Nyeri is much more homogeneous than is Nakuru. Nakuru is home to a wide variety of ethnic groups, whereas Nyeri is composed largely of Kikuyus and is primarily a Catholic area. ${ }^{10}$ Whereas Nakuru's ethnic diversity might allow girls more freedom to admit to being sexually experienced, Nyeri's close-knit, comparatively closed Catholic community might discourage frank reporting. Alternatively, the differences between Nakuru and Nyeri may be real. Nakuru experienced considerable ethnic unrest prior to and during the time of the survey. These disputes, between the Kalenjin and the Kikuyu, may have resulted in sufficient social disruption to increase sexual activity among girls.

In addition to investigating the internal consistency of the data on sexual initiation, the reporting in the survey was compared with that of the DHS. Although the DHS data are designed to be representative at the provincial but not at the district level, a comparison of the reports of sexual activity and marriage with those of the 1993 Kenya DHS in rural areas of Kilifi, Nakuru, and Nyeri are thought to be illuminating. ${ }^{11}$ Because the DHS does not include girls younger than 15 , the analysis is limited to those aged 15-19. 
The first row of Table 2 suggests that the reporting of sexual activity among the unmarried is lower in the adolescent survey compared with the DHS data, 22 percent versus 29 percent. The life-table probabilities shown in rows three and four indicate that the difference is concentrated at the older ages, that is, the level of reporting is the same for respondents aged 15-17, but comparison with the DHS suggests considerable underreporting of premarital sex among those 18 and 19. Some of this difference may simply be due to statistical noise resulting from small sample sizes. Some may be due to the possible selectivity of the 19-yearolds who were interviewed (see discussion above). The second row and the last two rows of the table indicate, however, that some of the difference might reflect the fact that a greater proportion of the adolescent survey sample reports being married. Judging from the comparison of the proportion reporting having had premarital sex, the married girls interviewed for the present study appear to be more inclined to report retrospectively that they experienced sex before marriage than the single girls are currently inclined to report having sex. Also, respondents

Table 2 Sexual activity and marriage in Kilifi, Nakuru, and Nyeri: 1993 Kenya DHS and 1996 adolescent survey

\begin{tabular}{lcc}
\hline Variable & 1993 DHS & Adolescent survey \\
\hline $\begin{array}{l}\text { Percent sexually active, never-married } \\
\text { girls aged 15-19 }\end{array}$ & 29 & 22 \\
Percent premaritally sexually active, & $(\mathrm{N}=174)$ & $(\mathrm{N}=150)$ \\
all girls aged 15-19 & 30 & 29 \\
Life-table probability of having premarital & .38 & $(\mathrm{~N}=192)$ \\
sex by age 17, all girls aged 15-19 & $(\mathrm{N}=207)$ & .39 \\
Life-table probability of having premarital & .68 & $(\mathrm{~N}=192)$ \\
sex by age 19, all girls aged 15-19 & $(\mathrm{N}=207)$ & .39 \\
Percent currently married girls & 16 & $(\mathrm{~N}=192)$ \\
aged 15-19 & $(\mathrm{N}=209)$ & 19 \\
Percent ever-married girls aged 15-19 & 17 & $(\mathrm{~N}=194)$ \\
& $(\mathrm{N}=209)$ & 23 \\
\hline
\end{tabular}


in this survey may be more comfortable reporting themselves as married if they have had sex, which would explain the greater proportions currently and ever married, compared with those of the DHS.

If underreporting of premarital sex occurs, the statistical analysis may be compromised. If the underreporting is systematic, then the parameter estimates and standard errors are biased; if it is not systematic, then the model is unbiased. The assumption is made here that to the extent underreporting occurs, it is not related in a consistent fashion to any of the explanatory variables included in the models.

\section{RESULTS}

The main outcome variable for the analysis is the odds of having premarital sex. The probability of practicing contraception among those who are sexually experienced is also investigated. Because of insufficient numbers of cases, the use of contraceptives is not timed relative to the initiation of sex; instead, ever use of contraceptives is analyzed.

\section{Selection of Independent Variables}

The independent variables can be separated conceptually into two groups: those that are individual and family characteristics and those that are school characteristics. An exhaustive list of variables in the model would have been desirable, but the small size of the adolescent and school samples limited the degrees of freedom available. In order to include as many potentially interesting elements of school quality as possible, the analysis of premarital sex was undertaken in two steps. The first model estimates individual and family determinants of premarital sex for boys and girls separately. In order to preserve all variables of potential interest, any variable that was significant at the $\mathrm{p}<0.20$ level was selected for inclusion in the model containing school-level variables. ${ }^{12}$

Below is a list of all individual and household variables that were considered for inclusion in the model: 
(1) Puberty (time-varying): $0=$ no; $1=$ yes (indicated for girls by the onset of menarche, and for boys experiencing nocturnal emission) ${ }^{13}$

(2) Age (time-varying): <14 (omitted), 14-16, 17-19

(3) Ethnicity: Kikuyu, Kalenjin, or other (omitted)

(4) District: Kilifi (omitted), Nakuru, and Nyeri

(5) Female-headed household: $0=$ no; $1=$ yes

(6) Lives with both parents: $0=$ no; $1=$ yes

(7) Household-possessions index (scale 0-10)

(8) Christian: $0=$ no; $1=$ yes

(9) Mother's education: < primary (omitted), completed primary, and secondary+

(10) Responsible adult thinks boys should have more education than girls: $0=$ no; $1=$ yes

For four independent variables - female-headed household, householdpossessions index, mother's education, and the responsible adult's attitude toward gender differences in educational attainment—missing-value dummy variables were included in order to minimize loss of cases due to missing data. All of these variables had a considerable number of cases with missing values.

Table 3 presents the results for the model of adolescents' experiencing premarital sex, including only the individual and household variables. Not unexpectedly, two variables that have large effects for both boys and girls are the time-varying variables, puberty and age. The odds of an adolescent's experiencing sex are much greater if he or she has reached puberty. The age at which first premarital sex is apparently most likely is $14-16$ for both boys and girls; however, underreporting is likely among girls and possibly, as indicated above, a selectivity effect may exist for boys in that the 19-year-olds who were interviewed are less mobile and less likely to be sexually active than are similar boys of this age. Other variables that are significant for girls, although at different levels, are district, female-headed household, and living with both parents. Con- 
Table 3 Logistic regression model of adolescents' experiencing premarital sex, by individual and family characteristics, Kenya, 1996

\begin{tabular}{|c|c|c|c|c|}
\hline \multirow[b]{2}{*}{ Variable } & \multicolumn{2}{|c|}{ Girls } & \multicolumn{2}{|c|}{ Boys } \\
\hline & Odds ratio & p-value & Odds ratio & p-value \\
\hline $\begin{array}{l}\text { Puberty (time-varying) } \\
\text { (omitted = no) }\end{array}$ & $11.29 * * *$ & 0.000 & $4.89 * * *$ & 0.000 \\
\hline \multicolumn{5}{|l|}{$\begin{array}{l}\text { Age }(\text { time-varying) } \\
\text { (omitted }=<14)\end{array}$} \\
\hline $14-16$ & $3.16^{*}$ & 0.021 & $2.53 * * *$ & 0.000 \\
\hline $17-19$ & 1.48 & 0.552 & 1.61 & 0.301 \\
\hline $\begin{array}{l}\text { Kikuyu or Kalenjin } \\
\text { (omitted = other) }\end{array}$ & 0.95 & 0.918 & 0.77 & 0.475 \\
\hline \multicolumn{5}{|l|}{$\begin{array}{l}\text { District } \\
\text { (omitted }=\text { Kilifi })\end{array}$} \\
\hline Nakuru & $7.78 * * *$ & 0.001 & 1.73 & 0.201 \\
\hline Nyeri & 1.50 & 0.569 & $2.10^{\Delta}$ & 0.116 \\
\hline \multicolumn{5}{|l|}{$\begin{array}{l}\text { Female-headed household } \\
\text { (omitted = no) }\end{array}$} \\
\hline Yes & $0.53^{\dagger}$ & 0.066 & 0.93 & 0.706 \\
\hline Missing & 0.59 & 0.406 & 1.63 & 0.429 \\
\hline $\begin{array}{l}\text { Living with both parents } \\
\text { (omitted = no) }\end{array}$ & $0.54^{\dagger}$ & 0.065 & $1.30^{\Delta}$ & 0.181 \\
\hline Household-possessions index & 0.91 & 0.346 & $0.93^{\Delta}$ & 0.129 \\
\hline Missing & 0.66 & 0.698 & 0.50 & 0.342 \\
\hline $\begin{array}{l}\text { Christian } \\
\text { (omitted = Muslim, other) }\end{array}$ & 0.63 & 0.410 & 0.95 & 0.872 \\
\hline \multicolumn{5}{|l|}{$\begin{array}{l}\text { Mother's education } \\
\text { (omitted = < primary) }\end{array}$} \\
\hline Completed primary & 1.45 & 0.275 & 1.20 & 0.411 \\
\hline Completed secondary & 0.69 & 0.549 & 1.25 & 0.446 \\
\hline Missing & 1.32 & 0.463 & 0.93 & 0.785 \\
\hline \multicolumn{5}{|l|}{$\begin{array}{l}\text { Responsible adult thinks boys } \\
\text { should have more education }\end{array}$} \\
\hline Missing & 3.57 & 0.154 & 1.30 & 0.614 \\
\hline$(\mathrm{N})$ & & & & \\
\hline
\end{tabular}

${ }^{\Delta}$ Significant at $\mathrm{p}<0.20 ;{ }^{\dagger} \mathrm{p}<0.10 ; * \mathrm{p}<0.05 ; *{ }^{*} \mathrm{p}<0.01 ; * * \mathrm{p}<0.001$. 
sistent with the descriptive data, the odds of having premarital sex are much higher for girls in Nakuru than for those living in the other two districts. Girls who live with both parents are less likely to experience premarital sex, perhaps because they are monitored more closely. Interestingly, girls who live in female-headed households are also less likely to have sex. Perhaps the presence of a female authority figure whom girls can look up to and whose voice counts in the household is a deterrent to engaging in sex. ${ }^{14}$ For boys, the only other variables significant at the $\mathrm{p}=0.20$ level are district, living with both parents, and the household-possessions index. Boys who live in Nyeri and who have a lower standard of living are at greater risk than others of having premarital sex. In contrast with girls, boys who live with both parents are surprisingly more likely to engage in premarital sex.

As indicated above, all individual and household variables with a p-value less than 0.20 were retained. For girls, the retained household- and individuallevel variables include puberty, age, female-headed household, and living with both parents. For boys, the retained household- and individual-level variables include puberty, age, living with both parents, and the household-possessions index. ${ }^{15}$

In contrast to the selection of individual and household variables, the selection of school variables was based almost entirely on theoretical considerations. From the school survey, 272 variables were produced that captured aspects of school quality. Those variables that the authors judged to be poorly measured or not reliably reported were discarded; those that might plausibly be associated with premarital sex and contraceptive use were selected. As indicated above, all of the variables selected here are drawn from two of the four dimensions of school quality that were included in the conceptual model: school and classroom dynamics and family-life education (Mensch and Lloyd 1998).

Below is a list of school-level variables that were included in the model of adolescents' experiencing premarital sex. The description of some variables is followed by "(boys/girls)," indicating that the variable in question is divided into two, one recording male students' responses and the other recording female stu- 
dents' responses; this description is used if the correlation between the boys' and girls' variables was lower than 0.7. In all such cases, the boys' variable has been included in the boys' model, the girls' variable in the girls' model.

\section{From Head Teacher Questionnaire}

- Does the head teacher favor a severe response to a teacher who has had sexual relations with a student? $0=$ no; $1=$ yes

- Does the head teacher approve of educating students about sexuality and/ or family planning in primary school? (scale $0-2$ )

- Does the head teacher think that pregnant girls should be allowed to stay in school until just before childbirth (girls' model only)? $0=$ no; $1=$ yes

- Does the head teacher favor a serious response to a male student who impregnates another student (boys' model only)? $0=$ no; $1=$ yes

\section{From Teacher Survey}

- Percentage of interviewed teachers who feel that math is an important subject for girls

- Percentage of interviewed teachers who do not express a preference for teaching boys (that is, who prefer teaching girls or who have no preference between boys and girls)

\section{From Classroom-observation Instrument}

- Average number of "good" or "positive" teacher-student interactions observed per class (for comparability across observed classes, number of events is standardized to a class of 40 minutes with 20 students of each sex)

From School-inventory Instrument

- Number of important family-life education subjects taught at the school (0-3)

\section{From Student Survey}

- Percentage of students who say that someone at the school gives advice and talks to students about their problems (boys/girls)

- Percentage of students who say that boys and girls are treated equally at the school (boys/girls)

- Percentage of girls who say that they were checked for pregnancy at the school after their last Easter holiday (girls' model only) 
- Average percentage of correct answers given by students concerning the questions on basic facts of sexuality and sexually transmitted diseases (boys/girls)

- Percentage of students reporting participation in clubs or societies

- Percentage of students reporting participation in sports at school (boys/girls)

- Percentage of students reporting that they were pressured to engage in sexual activity by someone at school (boys/girls)

- Average percentage of possible incidences of boys' harassment of girls at school that is reported by girls (girls' model only)

- Average percentage of possible incidences of girls' harassment of boys at school that is reported by boys (boys' model only)

Some of the variables - teachers' attitudes toward the importance of math for girls, the absence of a preference for teaching boys, girls' and boys' attitudes about equal treatment of the sexes in school, severe response to teacher-student sex, serious response to male students' making female students pregnant, and sexual and other types of harassment—reflect directly the degree to which the school environment is gender-sensitive. Other variables-average number of positive teacher-student interactions and presence of an advisor-reflect the degree to which the school is a congenial or supportive place in which to learn. Yet another set of variables - approval of sex and family planning education, approval of allowing pregnant girls to remain in school, number of family-life education subjects taught, pregnancy checks for girls, and students' reproductive knowledge-reflect administrators' views toward adolescent sexual and family planning behavior and the teaching of family-life education at school. A final pair of variables - club and sports participation - reflect the degree to which activities exist that occupy adolescents' time and that may bring boys and girls into contact.

\section{The Determinants of Premarital Sex}

A discrete-time hazard model of premarital sex was estimated using logistic regression with the period of observation starting at the earliest reported age of sexual debut. The few respondents who initiated sex before they started school 
were omitted from the final analysis, and individuals did not enter the analysis until the age they began attending school. The model includes the individual and household variables discussed above as well as 16 of 17 school variables; because of a problem with multicollinearity, after diagnostic analysis the harassment variable was removed from the boys' model. In order to account for the expanded sample resulting from the use of a person-year file, the robust standard errors available in the Stata statistical package were employed.

Table 4 presents the results for boys and girls separately. Because of the small sample size, variables significant at $\mathrm{p}<0.10$ are noted for all models. Interestingly, whereas no school variable is significant for boys, three school variables are signifi-

Table 4 Logistic regression model of adolescents' experiencing premarital sex, by individual, family, and school characteristics, Kenya, 1996

\begin{tabular}{|c|c|c|c|c|}
\hline \multirow[b]{2}{*}{ Variable } & \multicolumn{2}{|c|}{ Girls } & \multicolumn{2}{|c|}{ Boys } \\
\hline & Odds ratio & p-value & Odds ratio & p-value \\
\hline \multicolumn{5}{|c|}{ Individual and family characteristic } \\
\hline $\begin{array}{l}\text { Puberty (time-varying) } \\
\text { (omitted = no) }\end{array}$ & $11.84 * * *$ & 0.000 & $6.11 * * *$ & 0.000 \\
\hline \multicolumn{5}{|l|}{$\begin{array}{l}\text { Age (time-varying) } \\
\text { (omitted }=<14 \text { ) }\end{array}$} \\
\hline $14-16$ & 2.25 & 0.246 & $1.85^{*}$ & 0.044 \\
\hline $17-19$ & 2.01 & 0.429 & 0.83 & 0.761 \\
\hline $\begin{array}{l}\text { Kikuyu or Kalenjin } \\
\text { (omitted = other) }\end{array}$ & 2.98 & 0.205 & 1.12 & 0.786 \\
\hline \multicolumn{5}{|l|}{$\begin{array}{l}\text { Female-headed household } \\
\text { (omitted = no) }\end{array}$} \\
\hline Yes & $0.31 *$ & 0.036 & NA & NA \\
\hline Missing & 0.68 & 0.564 & NA & NA \\
\hline $\begin{array}{l}\text { Living with both parents } \\
\quad(\text { omitted = no) }\end{array}$ & $0.36^{\dagger}$ & 0.061 & 1.39 & 0.128 \\
\hline Household-possessions index & NA & NA & 0.98 & 0.799 \\
\hline Missing & NA & NA & 0.66 & 0.555 \\
\hline \multicolumn{5}{|l|}{ School characteristic } \\
\hline Head teacher & & & & \\
\hline $\begin{array}{l}\text { Severe response to } \\
\text { teacher-student sex } \\
(\text { omitted }=\text { no })\end{array}$ & 1.07 & 0.912 & 1.57 & 0.221 \\
\hline
\end{tabular}




\begin{tabular}{|c|c|c|c|c|}
\hline \multirow[b]{2}{*}{ Variable } & \multicolumn{2}{|c|}{ Girls } & \multicolumn{2}{|c|}{ Boys } \\
\hline & Odds ratio & p-value & Odds ratio & p-value \\
\hline $\begin{array}{l}\text { Approval of sex and family } \\
\text { planning education } \\
\text { (omitted }=\text { no) }\end{array}$ & 0.99 & 0.975 & 1.09 & 0.658 \\
\hline $\begin{array}{l}\text { Approval of presence of } \\
\text { pregnant girls in school } \\
\text { (omitted }=\text { no) }\end{array}$ & $2.03^{\dagger}$ & 0.089 & NA & NA \\
\hline $\begin{array}{l}\text { Serious response to } \\
\text { male student's impregnating } \\
\text { female student } \\
(\text { omitted }=\text { no) }\end{array}$ & NA & NA & 0.92 & 0.780 \\
\hline \multicolumn{5}{|l|}{ Teacher } \\
\hline $\begin{array}{l}\text { Math important for } \\
\text { girls (percent) }\end{array}$ & $0.72 * *$ & 0.003 & 1.02 & 0.689 \\
\hline $\begin{array}{l}\text { Preference for teaching } \\
\text { boys (percent) }\end{array}$ & 1.01 & 0.903 & 0.94 & 0.331 \\
\hline \multicolumn{5}{|l|}{ Classroom observation } \\
\hline $\begin{array}{l}\text { Average number of positive } \\
\text { teacher-student interactions }\end{array}$ & 0.99 & 0.679 & 0.99 & 0.212 \\
\hline \multicolumn{5}{|l|}{ School inventory } \\
\hline $\begin{array}{l}\text { Number of family-life education } \\
\text { subjects taught }(0-3)\end{array}$ & 0.85 & 0.694 & 0.75 & 0.220 \\
\hline \multicolumn{5}{|l|}{ Student } \\
\hline Presence of advisor (percent) ${ }^{\mathrm{a}}$ & 1.27 & 0.257 & 1.03 & 0.763 \\
\hline Equal gender treatment (percent) ${ }^{\mathrm{a}}$ & $0.57 *$ & 0.012 & 0.95 & 0.723 \\
\hline Pregnancy check (percent) & 1.28 & 0.824 & NA & NA \\
\hline $\begin{array}{l}\text { Reproductive health knowledge } \\
\text { (percent) }{ }^{\mathrm{a}}\end{array}$ & 0.60 & 0.253 & 1.08 & 0.755 \\
\hline $\begin{array}{l}\text { School clubs participation } \\
\text { (percent) }\end{array}$ & 0.96 & 0.855 & 0.90 & 0.16 \\
\hline Sports participation (percent) $)^{\mathrm{a}}$ & 1.37 & 0.265 & 1.11 & 0.170 \\
\hline Sexual harassment (percent) & $2.07 *$ & 0.037 & 1.01 & 0.960 \\
\hline $\begin{array}{l}\text { Other opposite-sex harassment } \\
\text { (percent) })^{\mathrm{a}}\end{array}$ & 0.78 & 0.324 & NA & NA \\
\hline$(\mathbf{N})$ & \multicolumn{2}{|c|}{$(262)$} & \multicolumn{2}{|c|}{$(258)$} \\
\hline \multicolumn{5}{|l|}{$\begin{array}{l}\text { Significance level of log-likelihood } \\
\text { test for model, adding school } \\
\text { characteristics as a block }\end{array}$} \\
\hline
\end{tabular}

a Variable measured separately for boys and girls. NA $=$ Not applicable.

${ }^{\dagger}$ Significant at $\mathrm{p}<0.10 ; * \mathrm{p}<0.05 ; * * \mathrm{p}<0.01 ; * * * \mathrm{p}<0.001$. 
cant for girls at $\mathrm{p}<0.05$ and one is significant at $\mathrm{p}<0.10$. When compared with a model that includes only individual and family variables, these school variables add significantly to the fit of the model for girls but not for boys. The log-likelihood test for the addition of the school variables indicates that they are jointly significant at $\mathrm{p}=$ 0.03 for girls. Girls are less likely to engage in premarital sex if they have attended schools where teachers take the importance of subjects like math seriously for girls, where girls feel they are being treated equitably, and where girls feel less sexual harassment. Interestingly, girls who attend schools where head teachers believe that pregnant girls should be able to remain enrolled are apparently more likely to engage in sex. This finding may result, however, from the variable's being endogenous. Schools that have more lenient policies with regard to pregnant students may simply be responding to a perceived problem. ${ }^{16}$

What is most noteworthy about the analyses of boys in Tables 3 and 4 is that few variables explain why they engage in sex. Sex for boys that have reached puberty appears to be opportunistic. When they have a chance to engage in sex, they do so. For girls, the decision to have sex is more complicated. For one thing, sex is often not volitional; for girls in this situation, no "decision" is involved. Among those who have some control over when and with whom they have sex, however, it is not entirely surprising that what sort of school they attend matters. Because in Kenya, as elsewhere in sub-Saharan Africa, sex often involves some bargaining or a commercial exchange (Calvès and Meekers 1997; Meekers and Calvès 1997), girls who are more empowered may be less likely to engage in sex. Skill in warding off boys and men seeking sex may derive in part from attendance at schools that are supportive of girls.

\section{The Determinants of Contraceptive Use}

The analysis of the determinants of contraceptive use involved the same procedure as did that for premarital sex. In order to select individual and family 
variables for inclusion in the model with school factors, a model was run with these variables alone, selecting the ones for the second stage that have a p-value less than 0.20 . Results for girls are not presented because severe collinearity problems were encountered due to the limited number of sexually experienced girls in the sample.

Table 5 presents the results of a logistic regression analysis of contraceptive use among sexually experienced boys, with individual and family characteristics included; Table 6 adds the school characteristics. Use of all methods ${ }^{17}$ and use of modern methods were investigated. As shown in Table 5, few individual and family variables are significant. Only age and mother's education meet the criterion for inclusion in the full model and the latter for the modern-methods model only. Boys who initiate sex later and whose mothers are better educated are more likely to use contraceptives. As for the models with school characteristics (see Table 6), a few tantalizing results are seen, but caution must be exercised in their interpretation because of the small size of the sample. Indeed, as a block, the school variables do not appear to add to the explanatory power of either model. For both the all-methods and the modern-methods models, the gender-equitable treatment variable and the reproductive health knowledge variable approach significance. Boys who have attended schools where students' knowledge of reproductive health is greater and where they perceive girls and boys to be treated equitably are more likely than those at other schools to practice contraception. The sports-participation variable is significant for the all-methods model. Boys who attend schools where they participate more in sports are less likely to use contraceptives than those at other schools, perhaps because participation in sports augments boys' social power and they are, therefore, more successful at demanding sexual favors from girls and better able to avoid the delays and inconvenience that contraceptive use may entail. 
Table 5 Logistic regression model of contraceptive use among premaritally sexually active boys, by individual and family characteristics, Kenya, 1996

\begin{tabular}{|c|c|c|c|c|}
\hline \multirow[b]{2}{*}{ Variable } & \multicolumn{2}{|c|}{ All methods } & \multicolumn{2}{|c|}{ Modern methods } \\
\hline & Odds ratio & p-value & Odds ratio & p-value \\
\hline $\begin{array}{l}\text { Puberty at time of sex } \\
\text { (omitted = no) }\end{array}$ & 1.37 & 0.453 & 1.58 & 0.280 \\
\hline \multicolumn{5}{|l|}{$\begin{array}{l}\text { Age at first sex } \\
\text { (omitted }=<14 \text { ) }\end{array}$} \\
\hline $14-16$ & $3.86 * * *$ & 0.001 & $1.71^{\Delta}$ & 0.194 \\
\hline $17-19$ & $7.98^{*}$ & 0.028 & $4.22^{\dagger}$ & 0.097 \\
\hline $\begin{array}{l}\text { Kikuyu or Kalenjin } \\
\text { (omitted = other) }\end{array}$ & 0.90 & 0.902 & 0.82 & 0.831 \\
\hline \multicolumn{5}{|l|}{$\begin{array}{l}\text { District } \\
\text { (omitted = Kilifi) }\end{array}$} \\
\hline Nakuru & 0.55 & 0.505 & 0.89 & 0.911 \\
\hline Nyeri & 1.20 & 0.861 & 2.03 & 0.534 \\
\hline $\begin{array}{l}\text { Female-headed household } \\
\text { (omitted = no) }\end{array}$ & 1.24 & 0.637 & 1.04 & 0.929 \\
\hline $\begin{array}{l}\text { Living with both parents } \\
\text { (omitted = no) }\end{array}$ & 0.67 & 0.362 & 0.59 & 0.226 \\
\hline Household-possessions index & 1.10 & 0.312 & 1.03 & 0.742 \\
\hline $\begin{array}{l}\text { Christian } \\
\text { (omitted = Muslim, other) }\end{array}$ & 0.60 & 0.351 & 0.88 & 0.834 \\
\hline \multicolumn{5}{|l|}{$\begin{array}{l}\text { Mother's education } \\
\text { (omitted = < primary) }\end{array}$} \\
\hline Completed primary & 1.73 & 0.229 & $1.86^{\Delta}$ & 0.180 \\
\hline Completed secondary & 1.60 & 0.498 & 2.28 & 0.221 \\
\hline Missing & 1.69 & 0.341 & $2.34^{\Delta}$ & 0.110 \\
\hline \multicolumn{5}{|l|}{$\begin{array}{l}\text { Responsible adult thinks boys } \\
\text { should have more education }\end{array}$} \\
\hline Missing & 1.35 & 0.762 & $0.27^{\Delta}$ & 0.119 \\
\hline$(\mathrm{N})$ & \multicolumn{2}{|c|}{ (158) } & \multicolumn{2}{|c|}{ (158) } \\
\hline
\end{tabular}

${ }^{\Delta}$ Significant at $\mathrm{p}<0.20 ;{ }^{\dagger} \mathrm{p}<0.10 ; * \mathrm{p}<0.05 ; * * \mathrm{p}<0.01 ; * * * \mathrm{p}<0.001$. 
Table 6 Logistic regression model of contraceptive use among boys, by individual, family, and school characteristics, Kenya, 1996

All methods

Modern methods

Variable

Odds ratio p-value

Odds ratio

p-value

Individual and family characteristic

Age at first sex

(omitted $=<14$ )

$$
14-16
$$

$3.58^{* * *}$

$4.23^{\dagger}$

0.005

1.92

0.146

$17-19$

0.098

2.99

0.206

Mother's education

(omitted $=<$ primary)

Completed primary

NA

NA

NA

2.35

0.142

Completed secondary

NA

$5.43 *$

0.039

Missing

NA

NA

2.32

0.210

\section{School characteristic}

Head teacher

Severe response to

teacher-student sex

(omitted $=$ no)

0.913

2.77

0.279

Approval of sex and family

planning education

0.534

1.75

0.150

(omitted $=$ no)

Serious response to male

student's impregnating

female student

0.186

1.97

0.325

(omitted $=$ no)

Teacher

Math important for girls

(percent)

0.91

0.549

0.86

0.348

Preference for teaching boys

(percent)

0.94

0.674

0.89

0.392

Classroom observation

Average number of positive

teacher-student interactions

1.03

0.382

1.04

0.222

School inventory

Number of family-life education

subjects taught $(0-3)$

0.126

1.43

0.480

Students

Presence of advisor

(percent) ${ }^{\mathrm{a}}$

0.92

0.707

0.89

0.568

Equal gender treatment (percent) ${ }^{\mathrm{a}}$

1.61

0.115

$1.70^{\dagger}$

0.096 


\begin{tabular}{|c|c|c|c|c|}
\hline \multirow[b]{2}{*}{ Variable } & \multicolumn{2}{|c|}{ All methods } & \multicolumn{2}{|c|}{ Modern methods } \\
\hline & Odds ratio & p-value & Odds ratio & p-value \\
\hline $\begin{array}{l}\text { Reproductive health knowledge } \\
\text { (percent) }^{\mathrm{a}}\end{array}$ & $2.78^{\dagger}$ & 0.077 & 2.41 & 0.104 \\
\hline $\begin{array}{l}\text { School clubs participation } \\
\text { (percent) }\end{array}$ & 1.02 & 0.923 & 0.91 & 0.543 \\
\hline Sports participation (percent) ${ }^{\mathrm{a}}$ & $0.70 *$ & 0.018 & 0.85 & 0.313 \\
\hline $\begin{array}{l}\text { Has been pressured to have } \\
\text { sex (percent) }\end{array}$ & 0.86 & 0.549 & 1.03 & 0.894 \\
\hline$(\mathbf{N})$ & \multicolumn{2}{|c|}{$(123)$} & \multicolumn{2}{|c|}{$(123)$} \\
\hline $\begin{array}{l}\text { Significance level of log-likelihooc } \\
\text { test for model, adding school } \\
\text { characteristics as a block }\end{array}$ & \multicolumn{2}{|c|}{0.352} & \multicolumn{2}{|c|}{0.486} \\
\hline
\end{tabular}

a Variable measured separately for boys and girls. NA $=$ Not applicable

${ }^{\dagger}$ Significant at $\mathrm{p}<0.10 ; * \mathrm{p}<0.05 ; * * \mathrm{p}<0.01 ; * * * \mathrm{p}<0.001$.

\section{Timing of Premarital SEX AND PREgnanCy With SCHOOL DROPOUT}

As noted earlier, "schoolgirl pregnancy" is frequently discussed in Kenya. Generally, the problem is mentioned in connection with girls who drop out of school, and in such cases, the assumption usually is made that pregnancy precedes and causes school leaving (Meekers et al. 1995). Policymakers interested in increasing the number of girls who remain in school have, therefore, been led to focus on ways of discouraging school-age girls from becoming pregnant.

However, another possible explanation for the perceived connection between school dropout and adolescent pregnancy is that girls, finding school an unsatisfactory environment, are discouraged from continued attendance and drop out, and that such girls subsequently become pregnant, for any number of reasons. In such cases, the effort to make schools more congenial to girls, rather than to keep them from becoming pregnant, would suggest itself as a course of action for retaining girls in school.

The authors hoped to shed light on the relationship between pregnancy and 
dropout among Kenyan schoolgirls. The one complication is that the girls interviewed may have underreported the incidence of pregnancy. ${ }^{18}$ Generally, those who believe that surveys such as this one underreport pregnancy assume that such underreporting applies primarily to miscarriages and abortions- that is, to pregnancies that may not have come to public attention. Once a girl's pregnancy is known to her community - when it has continued to the point that it is visible or when the girl has given birth-she would appear to have little reason to conceal the pregnancy from researchers. In the present study, however, the focus is not on pregnancy per se, but rather on pregnancy that may be connected with school dropout. Because a pregnancy that leads to dropout is less likely to be a concealed pregnancy (the fact of its leading to dropout would call attention to it), that other (less public) pregnancies may have gone unreported in this survey may not be of great concern. ${ }^{19}$ Pregnancies leading to dropout are more likely to be known, and known pregnancies are likely to be reported. Therefore, even if the study did not fully record pregnancies overall, it is likely to have registered most pregnancies of interest.

Of the 360 girls in the sample, 36, or 10 percent, report ever having been pregnant. Among these girls, the association between pregnancy and school leaving is strong: All 36 have dropped out of school.

A look at the timing of pregnancy and school leaving, however, makes clear that the simple statement "pregnancy leads to dropout" is far from accurate. Of the 36 girls who have ever been pregnant and have left school, all but one give a valid age at which they dropped out. Among the 35 who list a valid age, 21 (60 percent) became pregnant at least one year after leaving school, nine (26 percent) became pregnant at the same time that they left school, and only five (14 percent) became pregnant before leaving school. Thus, even when girls who have become pregnant are considered independently of the large majority of girls who have not, pregnancy could have been a cause of dropout in a maximum of 40 percent of these cases. In all probability, the proportion of dropouts that can be attributed directly to pregnancy is much smaller than this (see Figure 2). 
Furthermore, when the 36 girls who ever attended school and who ever became pregnant were asked why they left school, only five (14 percent) listed pregnancy as the main reason. The other 31 listed reasons such as "could not pay fees" (18) and "lack of interest" (3). Overall, of the 96 girls in the sample who had stopped attending school, only five (5 percent) listed pregnancy as the main reason for school leaving, which is consistent with the proportion of dropouts who reported a pregnancy date prior to the time of dropout. Although this figure probably represents a low estimate of the proportion of dropouts due to pregnancy, if those who became pregnant at the same time that they left school were included, the proportion of dropouts attributable to pregnancy would only rise to 15 percent of all dropouts. In short, the majority of girls who dropped out of school did not leave because of pregnancy. Several other reasons were cited more

Figure 2 Relationship between pregnancy and schoolgirl dropout as reported by girls interviewed, Kenya, 1996

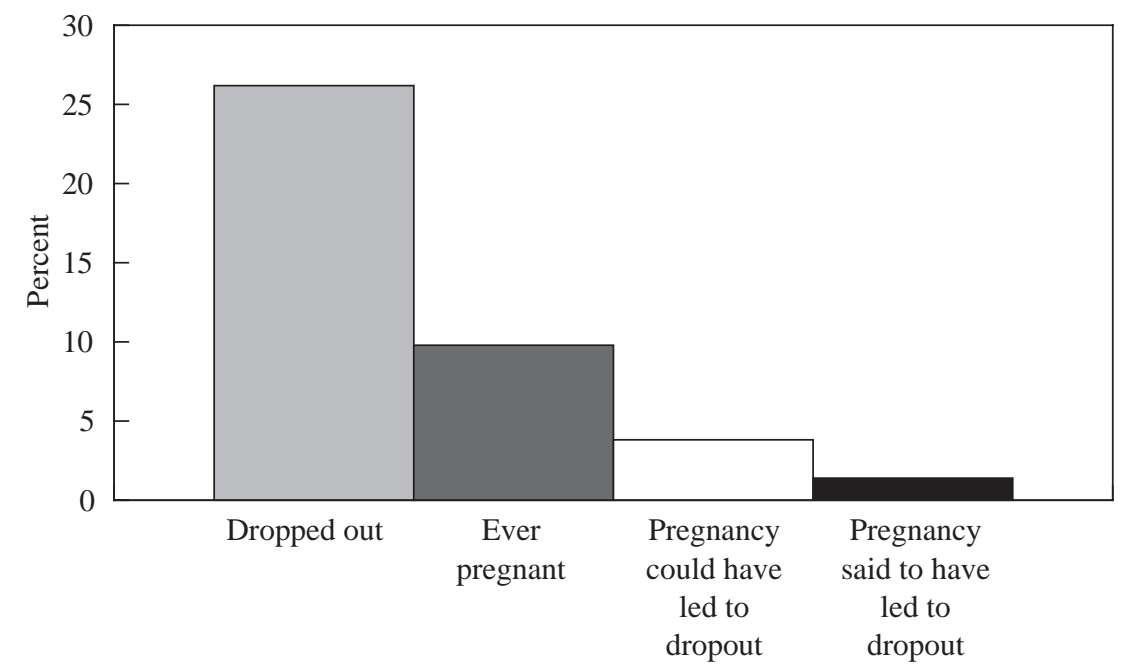

Girls $(\mathrm{N}=360)^{\mathrm{a}}$

${ }^{\mathrm{a}}$ Excludes one girl who attended school and became pregnant, but who did not list a valid age for pregnancy. 
frequently, including inability to pay fees (45 girls), having finished primary or secondary school (13), lack of interest (9), poor performance (6), and illness (6). Despite the small sample size for this analysis, on a purely descriptive level the data suggest that, although pregnancy and noncontinuation of school are strongly associated, pregnancy is not a central cause of schoolgirl dropout.

Because the data are censored, life tables were run to predict the overall likelihood of dropout for girls, followed by cause-specific life tables to predict dropout for various specific reasons. Although more than 82 percent of the girls in the model would be expected to have left school by the end of age 19, a mere 3 percent are predicted to have left as a result of pregnancy, a conclusion based on the reasons the girls gave for leaving (see Figure 3). Again, the data suggest that pregnancy is not a principal cause of schoolgirl dropout.

Finally, to address as conservatively as possible the issue of underreporting of pregnancy among girls in the sample, the relationship between premarital sex ${ }^{20}$ (a much more common phenomenon than adolescent pregnancy) and schoolgirl dropout was examined. Using a logistic regression model (in which a number of

Figure 3 Predicted relationship between pregnancy and schoolgirl dropout, Kenya, 1996 ( $\mathrm{N}=361)$

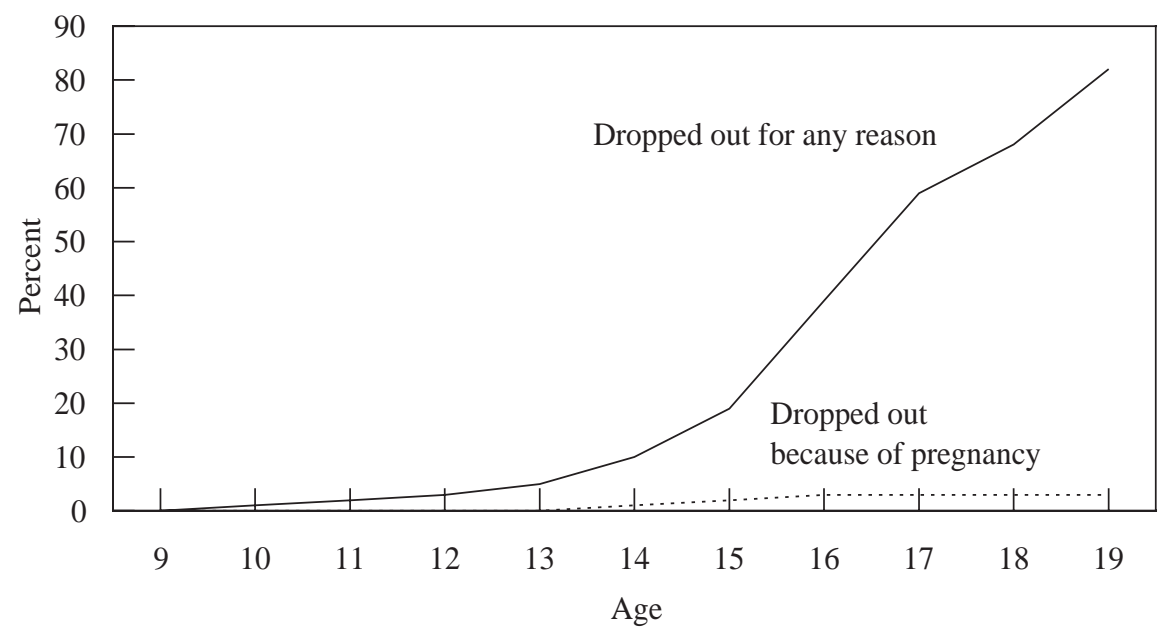


standard background variables were included) and converting the data to a person-year file, dropout was first considered as a time-varying variable predicting the odds of premarital sex (Table 7), and premarital sex was considered as a timevarying variable predicting the odds of dropout (Table 8). ${ }^{21}$ In both cases, the relationship was positive and significant $(\mathrm{p}=0.001)$. The odds ratio for dropout as a predictor of premarital sex (3.64), however, was more than two times the size of the odds ratio for premarital sex as a predictor of dropout (1.46).

Table 7 Logistic regression model of girls' experiencing premarital sex, by individual and family characteristics and dropout status, Kenya, 1996

Girls

Variable

Puberty (time-varying)

(omitted $=$ no)

Age (time-varying)

(omitted $=<14$ )

$$
14-16
$$$$
\text { 17-19 }
$$

Kikuyu or Kalenjin

(omitted $=$ other)

Female-headed household

(omitted $=$ no)

Yes

Missing

Living with both parents

1.93

.53

$2.57 *$

(omitted $=$ no)

Dropped out of school (time-varying)

(omitted $=$ no)

(N)
$0.41 * *$

0.80

0.60

.001

${ }^{\top}$ Significant at $\mathrm{p}<0.10 ;{ }^{*} \mathrm{p}<0.05 ; * * \mathrm{p}<0.01 ; * * * \mathrm{p}<0.001$. 
Table 8 Logistic regression model of school dropout among girls, by individual and family characteristics and whether or not respondent reported having had premarital sex, Kenya, 1996

\section{Girls}

Variable

Odds ratio

p-value

Puberty (time-varying)

$2.83^{* *}$

0.007

(omitted $=$ no)

Age (time-varying)

(omitted $=<14$ )

14-16

$8.51 * * *$

0.000

17-19

$22.25 * * *$

0.000

Kikuyu or Kalenjin

$0.46^{* *}$

0.002

(omitted $=$ other)

Female-headed household

(omitted $=$ no)

Yes

$0.53^{\dagger}$

0.063

Missing

$1.94^{\dagger}$

0.100

Living with both parents

$0.34 * * *$

0.000

(omitted $=$ no)

Had premarital sex (time-varying)

$1.46^{* * *}$

0.001

$($ omitted $=$ no $)$

(N)

${ }^{\dagger}$ Significant at $\mathrm{p}<0.10 ;{ }^{*} \mathrm{p}<0.05 ; * * \mathrm{p}<0.01 ; * * \mathrm{p}<0.001$.

Although questions about the reliability and structure of the data set preclude any absolute pronouncements about the significance of pregnancy as a cause of school leaving among Kenyan girls, the data strongly suggest that pregnancy is not a major reason for dropout. Girls appear to be more likely to leave school and become pregnant afterward than to become pregnant and, as a result, leave school. Efforts focused on making schools a more affordable, effective, and in- 
viting option for girls may do more to promote retention of girls than will efforts directed at preventing adolescent pregnancy, however important and valuable such efforts may be.

\section{CONCLUSION}

The study data present a fairly clear picture: Boys—-for whom early sexual experience has relatively few hazards and many potential benefits, including gratification and social prestige - appear to engage in premarital sex largely independent of the influence of their environment. The sexual activity of girls, on the other hand-for whom early sexual relations are fraught with a number of dangers, physical as well as social-appears to be more subject to environmental influences. A home containing authoritative female role models and the support of two parents, and a school characterized by teachers supportive of girls and a gender-neutral atmosphere, appear to help minimize premarital sexual behavior among girls. On the other hand, and not surprisingly, schools where girls feel pressured to engage in sexual activity appear to be associated with more of such behavior.

Furthermore, to the extent that the school environment has been modeled successfully here, it appears also to have an impact on whether sexually active boys choose to practice contraception. A perceived gender-neutral environment also is associated with positive results (the greater odds of using contraceptives), as is greater knowledge of sexual and reproductive health. Greater participation in school sports-which may increase boys' social power in relation to girls-is associated with lower contraceptive use.

Finally, although the data do not permit definitive statements about the association between pregnancy and school dropout, they suggest that even if certain school characteristics place girls at heightened risk of engaging in premarital sex, pregnancy is not the primary reason that girls in this Kenyan sample leave school early. 


\section{Appendix}

The initial fieldwork for this study took place in May and June of 1996. Two developments during this period threatened to reduce the size of the adolescent sample below acceptable levels. The first was the loss of households that had been categorized erroneously as having an adolescent in residence during the initial listing. The field team determined that no one between the ages of 12 and 19 in fact resided in these households. ${ }^{22}$ The second was poor response in certain clusters. Whereas the aggregate completion rate was between 76 and 78 percent for all three districts (as shown in the appendix table below), in three clusters out of seven in both Nyeri and Nakuru, the completion rate was below 70 percent. ${ }^{23}$ As a result, in August another attempt was made to interview selected adolescents who had not been home during earlier visits (whether because they attended boarding school, were working, or were absent temporarily). The sample was expanded by visits to the perimeter of each cluster with a low preliminary response rate in Nakuru and Nyeri and by sampling one household along the

Appendix Table 1 Household interviews, by survey characteristics, according to district, Kenya, 1996

\begin{tabular}{lrrr}
\hline Characteristic & Kilifi & Nakuru & Nyeri \\
\hline $\begin{array}{l}\text { Number of adolescents } \\
\text { originally listed }\end{array}$ & 329 & 329 & 295 \\
Number of adolescents out of age range & 13 & 12 & 28 \\
Duplicate of adolescent interview & 1 & 3 & 2 \\
Number of adolescents after & & & \\
subtracting those out of age range and duplicates & 315 & 314 & 265 \\
Number of adolescents initially interviewed & 247 & 240 & 206 \\
Completion rate (percent) & 78 & 76 & 78 \\
Number of adolescents added to sample in August & 0 & 53 & 28 \\
Total adolescent sample & 247 & 293 & 234 \\
\hline
\end{tabular}


perimeter, as had been done for the other households. In this way, 53 households and adolescents were added in Nakuru and 28 in Nyeri to yield a final sample of 774: 247 in Kilifi, 293 in Nakuru, and 234 in Nyeri.

\section{Notes}

1 According to two population-based epidemiological studies, one in Tanzania, the other in Uganda, HIV prevalence rates among females aged 15-24 were 13-17 percent, compared with 5 percent among boys in the same age group. The differential is considered to be a result of the age difference in their sexual partners (Borongo et al. 1992; Nunn et al. 1994. See also KondeLule et al. 1997).

2 See Görgen et al. 1998 for urban Guinea; Matasha et al. 1998 for school students in Mwanza Region, Tanzania; Kane et al. 1993 for urban Gambia; Ajayi et al. 1991 for Kenya; Boohene et al. 1991 for urban Zimbabwe; and Gage-Brandon and Meekers 1993 for six DHS countries.

3 Many of the studies listed in Table 1 did not report the levels of sexual activity shown. Most often the percentages were reported separately for different sub-groups. The authors of this study combined different groups, for example, students and nonstudents; and older and younger adolescents, in order to present an aggregate level.

4 In an analysis of ten-year-old DHS data from Botswana, Meekers and Ahmed (1999) note that, although the risk of dropping out of school as a result of pregnancy is low for primary school, it is much more common in secondary school. In choosing to focus on the risky sexual behavior of today's young people, Meekers and Ahmed ignore other causes of school dropout, which their own analysis indirectly shows are increasingly im- 
portant. Indeed, because pregnancy-related dropout declined in Botswana among those aged 15-34 in 1988 compared with those aged 35-49, clearly dropout due to pregnancy is quantitatively less important today.

5 This estimate is based on a 1987 survey of primary and secondary schools in Kenya intended to gather data on dropouts due to pregnancy. Because the report based on that survey provided no data on total dropouts or dropouts due to other causes, calculating what percentage of dropouts can be attributed to pregnancy is not possible (Ferguson 1988).

6 Computations were performed by the authors of this study. The survey, which was undertaken in 1992 under the auspices of the African Medical and Research Foundation, was conducted with technical assistance from the Population Council. For more information, see Youri (1994).

7 Schools were selected based on a preliminary household listing in which adolescents and the schools they attended were identified by an adult prior to conducting the community survey.

8 Alternatively, household members or interviewers displace respondents out of the group eligible for the interview, although this is not likely to be the case here, because the selection of candidates for the interview took place several months before the interview was conducted. Those who responded to the listing were never told that a survey that targeted 12-19-year-olds would be conducted eventually.

9 Adolescents who attended the three single-sex schools were excluded from the sample because the authors wanted to include variables that compared boys' and girls' experiences at the same schools. 
10 Although it may affect reporting of sexual behavior, Catholicism itself appears to have little effect on sexual and contraceptive behavior in Nyeri. Nyeri is the district in Kenya with the highest level of modern contraceptive use; more than 60 percent of women aged 15-49 there are currently using a modern method, a prevalence at least ten points higher than those of the other 16 districts included in the DHS analysis (see NCPD et al. 1999: Table 4.7).

11 Although the final report was available, the 1998 DHS data were not available at the time this paper was written.

12 If a missing-data variable was significant at $\mathrm{p}<0.20$ or lower but its associated main variable was not significant, neither the main nor the missingdata variable was included in further analysis.

13 Although "age at nocturnal emission" is included, this event is less salient for boys than is first menses for girls, and may have been more likely to be misreported. An alternative variable, age at male circumcision, might have been a better choice had circumcision been universal and had it always occurred during puberty, because for some groups circumcision has considerable cultural significance, and boys are pressured to have sex soon after it takes place. However, of the 254 boys in the sample who had been circumcised (including those who did not attend the schools visited), 35 percent had been circumcised prior to age 12 .

14 The correlation (not shown) between the two variables "female-headed household" and "living with both parents" is surprisingly low: -0.48 . Clearly, these two variables are measuring different familial conditions. Living in a household headed by a woman does not preclude having a father present. 
15 Note that district is not included in the retained list of variables despite its being significant at $\mathrm{p}<0.20$. When district was included in the models with school-level variables, instabilities became apparent in the results that were consistent with a multicollinearity problem. By means of the "fit" and "vif" commands in the Stata program (StataCorp 1997), this problem was determined likely to center on the variables for district of residence. As a result, these variables were removed from the model and a variable substituted that measures whether or not an individual is a member of the Kikuyu or Kalenjin tribe- - two dominant ethnic groups in Kenya. Although this measure is by no means the same as that for district of residence, it appears to capture some background similarities among respondents that may have a bearing on sexual behavior.

16 When this potentially endogenous variable was excluded, the coefficients and standard errors for the other variables barely changed.

17 The category "all methods" of contraceptive use includes "withdrawal," "safe days," and "natural family planning," as well as modern methods.

18 Pregnancy rates among girls in the sample are similar to those reported among the comparable subsample of the 1993 Kenya DHS. As indicated earlier in the comparison of the sexual activity data, however, the DHS subsample on its own (separated from the DHS as a whole) may not be representative. Moreover, problems with underreporting may have occurred in the DHS. Thus, despite the similarity with the DHS data, the authors of the present study are not entirely confident that they received a full accounting of pregnancy from the girls surveyed.

19 If, however, the pregnancy is aborted and the abortion leads to complica- 
tions and hospitalization, it may not be reported, although the girl may have dropped out of school as a result.

20 Marital sex was not included in this examination, because girls generally appear to leave school before or at the time of marriage. In such cases, early marriage, rather than marital sex or childbearing, is most likely to be the proximate cause of school leaving.

21 The two models differed in that, in the first, cases left the model as soon as dropout had occurred, whereas in the second, cases were removed as soon as premarital sex had occurred.

22 Moreover, although only one adolescent was designated to be interviewed per household, for six households interviews were conducted with two adolescents.

23 The initial completion rate was computed as follows: first the "out of the age range" and duplicate adolescents were subtracted from those originally listed in order to determine the denominator. The number interviewed then was divided by the denominator.

\section{References}

Ajayi, Ayo A., Leah T. Marangu, Janice Miller, and John M. Paxman. 1991. "Adolescent sexuality and fertility in Kenya: A survey of knowledge, perception, and practices," Studies in Family Planning 22(4): 205-216.

Ajayi, Ayorinde et al. 1997. Schooling and the Experience of Adolescents in Kenya. Nairobi: Population Council and the Government of Kenya Ministry of Education.

Amazigo, Uche, Nancy Silva, Joan Kaufman, and Daniel S. Obikeze. 1997. "Sexual activity and contraceptive knowledge and use among in-school 
adolescents in Nigeria," International Family Planning Perspectives 23(1): 28-33.

Blanc, Ann K. and Ann A. Way. 1998. "Sexual behavior and contraceptive knowledge and use among adolescents in developing countries," Studies in Family Planning 29(2): 106-116.

Bledsoe, Caroline H. 1990. "School fees and the marriage process for Mende girls in Sierra Leone," in Peggy R. Sanday and Ruth G. Goodenough (eds.), New Directions in the Anthropology of Gender. Philadelphia: University of Pennsylvania Press, pp. 283-309.

Bledsoe, Caroline H. and Barney Cohen. 1993. Social Dynamics of Adolescent Fertility in Sub-Saharan Africa. Washington, DC: National Academy Press.

Boohene, Esther et al. 1991. "Fertility and contraceptive use among young adults in Harare, Zimbabwe," Studies in Family Planning 22(4): 264-271.

Borongo, Longin R. et al. 1992. "The epidemiology of HIV-1 infection in urban areas, roadside settlements, and rural villages in Mwanza, Tanzania," AIDS 6(12): 1,521-1,528.

Caldwell, John C., I.O. Orubuloye, and Pat Caldwell. 1992. "Fertility decline in Africa: A new type of transition?" Population and Development and Review 18(2): 211-243.

Calvès, Anne-Emmanuèle and Dominique Meekers. 1997. "Gender differentials in premarital sex, condom use, and abortion: A case study of Yaoundé, Cameroon," PSI Research Division Working Paper No. 10. Washington, DC: Population Services International.

Erulkar, Annabel S. and Barbara S. Mensch. 1997. "Gender differences in the dating experiences and sexual behavior of adolescents in Kenya.” Paper presented at the $23^{\text {rd }}$ Conference of the International Union for the Scientific Study of Population, 11-17 October, Beijing.

Ferguson, Alan. 1988. Schoolgirl Pregnancy in Kenya: Report of a Study of 
Discontinuation Rates and Associated Factors. Nairobi: Division of Family Health, Kenyan Ministry of Health.

Gage-Brandon, Anastasia J. and Dominique Meekers. 1993. "Sex, contraception, and childbearing before marriage in sub-Saharan Africa," International Family Planning Perspectives 19(1): 14-18, 33.

Görgen, Regina, Mohamed L. Yansané, Michael Marx, and Dominique Millimounou. 1998. "Sexual behavior and attitudes among unmarried urban youths in Guinea," International Family Planning Perspectives 24(2): $65-71$.

Kane, Thomas T. et al. 1993. "Sexual activity, family life education, and contraceptive practice among young adults in Banjul, The Gambia," Studies in Family Planning 24(1): 50-61.

Kenyatta, Jomo. 1971. Facing Mount Kenya: The Tribal Life of the Gikuyu. London: Secker and Warburg.

Kiragu, Karungari and Laurie S. Zabin. 1993. "The correlates of premarital sexual activity among school-age adolescents in Kenya," International Family Planning Perspectives 19(3): 84-97, 109.

- 1995. "Contraceptive use among high school students in Kenya," International Family Planning Perspectives 21(3): 108-113.

Konde-Lule, Joseph K., N. Sewankambo, and Martina Morris. 1997. "Adolescent sexual networking and HIV transmission in rural Uganda," Health Transition Review 7 (Supplement): 89-100.

Lloyd, Cynthia B. and Barbara S. Mensch. 1999. "Implications of formal schooling for girls' transitions to adulthood in developing countries," in Caroline H. Bledsoe, John B. Casterline, Jennifer A. Johnson-Kuhn, and John G. Haaga (eds.), Critical Perspectives on Schooling and Fertility in the Developing World. Washington, DC: National Academy Press, pp. 80-106. 
Lloyd, Cynthia B., Barbara S. Mensch, and Wesley H. Clark. 1998. "The effects of primary school quality on the educational participation and attainment among Kenyan girls and boys," Policy Research Division Working Paper No. 116. New York: Population Council.

Matasha, E. et al. 1998. "Sexual and reproductive health among primary and secondary school pupils in Mwanza, Tanzania: Need for intervention," AIDS Care 10(5): 571-582.

Meekers, Dominique. 1992. "The process of marriage in African societies: A multiple indicator approach," Population and Development Review 18(1): 61-78.

- 1994. "Sexual initiation and premarital childbearing in sub-Saharan Africa," Population Studies 48(1): 47-64.

Meekers, Dominique and Ghyasuddin Ahmed. 1999. "Pregnancy-related school dropouts in Botswana," Population Studies 53(2): forthcoming.

Meekers, Dominique and Anne-Emmanuèle Calvès. 1997. “ 'Main' girlfriends, girlfriends, marriage, and money: The social context of HIV risk behaviour in sub-Saharan Africa," Health Transition Review 7 (Supplement): 361375.

Meekers, Dominique, Anastasia Gage, and Li Zhan. 1995. "Preparing adolescents for adulthood," Population Research and Policy Review 14(1): 91110.

Mensch, Barbara S., Judith Bruce, and Margaret E. Greene. 1998. The Uncharted Passage: Girls'Adolescence in the Developing World. New York: Population Council.

Mensch, Barbara S. and Cynthia B. Lloyd. 1998. "Gender differences in the schooling experiences of adolescents in low-income countries: The case of Kenya," Studies in Family Planning 29(2): 167-184. 
Montgomery, Mark R. and Cynthia B. Lloyd. 1999. "Excess fertility, unintended births, and children's schooling," in Caroline H. Bledsoe, John B. Casterline, Jennifer A. Johnson-Kuhn, and John G. Haaga (eds.), Critical Perspectives on Schooling and Fertility in the Developing World. Washington, DC: National Academy Press, pp. 216-266.

Munyiri, Stephen and Macharia Wa Mwati. 1996. "Gang rapes schoolgirls," The Nation: 40.

National Council for Population and Development (NCPD), Central Bureau of Statistics (CBS), and Macro International. 1994. Kenya Demographic and Health Survey 1993. Calverton, MD: NCPD, CBS, and Macro International.

- 1999. Kenya Demographic and Health Survey 1998. Calverton, MD: NCPD, CBS, and Macro International.

Njau, Wangoi and Sheila Wamahiu. 1994. "Ministerial consultation on school dropout and adolescent pregnancy under the theme: 'Counting the cost."' Background paper organized by the Forum for African Women Educationalists in collaboration with the Ministry of Education and Science, Mauritius.

Nunn, Andrew J. et al. 1994. "Risk factors of HIV-1 infection in adults in a rural Ugandan community: A population study," AIDS 8, no. 1: 81-86.

Odaga, Adhiambo and Ward Heneveld. 1995. "Girls and schools in sub-Saharan Africa: From analysis to action,” World Bank Technical Paper No. 298, Africa Technical Department Series. Washington, DC: The World Bank.

Singh, Susheela. 1998. "Adolescent childbearing in developing countries: A global review," Studies in Family Planning 29(2): 117-136.

StataCorp. 1997. "Regression fit and diagnostics," in Stata Statistical Software: Release 5.0. College Station, TX: Stata Press, pp. 372-396.

Youri, Pat (ed.). 1994. Female Adolescent Health and Sexuality in Kenyan Sec- 
ondary Schools: A Research Report. Nairobi: African Medical and Research Foundation.

Zabin, Laurie S. and Karungari Kiragu. 1998. "The health consequences of adolescent sexual and fertility behavior in sub-Saharan Africa," Studies in Family Planning 29(2): 210-232. 


\title{
POLICY RESEARCH DIVISION WORKING PAPERS
}

\author{
Recent Back Issues
}

\section{7}

93 James F. Phillips, Fred N. Binka, Martin Adjuik, Alex Nazzar, and Kubaze Frank Adazu, "The determinants of contraceptive innovation: A case-control study of family planning acceptance in a traditional African society."

*94 John Bongaarts and Sajeda Amin, "Prospects for fertility decline and implications for population growth in South Asia."

95 Barbara S. Mensch and Cynthia B. Lloyd, "Gender differences in the schooling experiences of adolescents in low-income countries: The case of Kenya."

96 Martin Brockerhoff and Ellen Brennan, "The poverty of cities in the developing world."

*97 Carol E. Kaufman, "Reproductive control in South Africa."

*98 John Bongaarts, "Trends in unwanted childbearing in the developing world."

99 Mary Arends-Kuenning, "How do family planning workers' visits affect women's contraceptive behavior in Bangladesh?"
100 Mark R. Montgomery and Cynthia B. Lloyd, "Excess fertility, unintended births, and children's schooling."

101 Mary Arends-Kuenning, "The equity and efficiency of doorstep delivery of contraceptives in Bangladesh."

*102 Sajeda Amin, Ian Diamond, Ruchira T. Naved, and Margaret Newby, "Transition to adulthood of female factory workers: Some evidence from Bangladesh."

*103 Margaret E. Greene and Ann E. Biddlecom, "Absent and problematic men: Demographic accounts of male reproductive roles."

104 Michael P. Todaro, "Urbanization, unemployment, and migration in Africa: Theory and policy."

105 Geoffrey McNicoll, "Population and poverty: A review and restatement."

\footnotetext{
* No longer available
} 
106 Sajeda Amin and Gilda Sedgh, "Incentive schemes for school attendance in rural Bangladesh.”

107 Martin Brockerhoff and Paul Hewett, "Ethnicity and child mortality in subSaharan Africa."

108 Ann E. Biddlecom and Bolaji M. Fapohunda, "Covert contraceptive use: Prevalence, motivations, and consequences."

109 John Bongaarts and Griffith Feeney, "On the quantum and tempo of fertility."

110 Barbara S. Mensch, Daniel Bagah, Wesley H. Clark, and Fred Binka, "The changing social environment for adolescents in the Kassena-Nankana District of northern Ghana: Implications for reproductive behavior."

111 Martin Brockerhoff and Ann Biddlecom, "Migration, sexual behavior, and HIV diffusion in Kenya."

112 Zeba A. Sathar and John B. Casterline, "The onset of fertility transition in Pakistan."

113 Geoffrey McNicoll, "Government and fertility in transitional and post-transitional societies."
114 John Bongaarts, "Fertility and reproductive preferences in post-transitional societies."

115 Fiona Steele, Sajeda Amin, and Ruchira T. Naved, "The impact of an integrated micro-credit program on women's empowerment and fertility behavior in rural Bangladesh."

*116 Cynthia B. Lloyd, Barbara S. Mensch, and Wesley H. Clark, "The effects of primary school quality on the educational participation and attainment of Kenyan girls and boys."

117 Sajeda Amin and Cynthia B. Lloyd, "Women's lives and rapid fertility decline: Some lessons from Bangladesh and Egypt."

118 James F. Phillips and Mian Bazle Hossain, "The impact of family planning household service delivery on women's status in Bangladesh."

119 Mark R. Montgomery and John B. Casterline, "Social networks and the diffusion of fertility control."

* No longer available 
120 John Bongaarts, "The fertility impact of changes in the timing of childbearing in the developing world."

121 James F. Phillips, Wendy L. Greene, and Elizabeth F. Jackson, "Lessons from community-based distribution of family planning in Africa."

122 Mark R. Montgomery, "Mortality decline and the demographic response: Toward a new agenda."
123 Mark R. Montgomery, Mary ArendsKuenning, and Cem Mete, "The quantity-quality transition in Asia."

124 Barbara S. Mensch, Wesley H. Clark, Cynthia B. Lloyd, and Annabel S. Erulkar, "Premarital sex and school dropout in Kenya: Can schools make a difference?" 